\title{
Daily and social activities influence the quality of life of renal chronic patients in hemodialysis
}

\author{
Atividades diárias e sociais influenciam a qualidade de vida de \\ pacientes renais crônicos em hemodiálise
}

Antonio Batista da Silva Filho ${ }^{1}$, Camila dos Santos Xavier ${ }^{1}$, Carolina Guilherme dos Santos ${ }^{1}$, Luiza Franco Corá2 Marcela Machado Fonseca ${ }^{1}$, Amanda Silveira Denadai ${ }^{1}$, Kennio Ferreira-Paim ${ }^{3}$, Fernanda Machado Fonseca ${ }^{1}$

\begin{abstract}
Objective: This study aimed to evaluate the physical and social factors that influence the quality of life of patients with chronic kidney disease (CKD) on hemodialysis (HD). Study Design: Descriptive and cross-sectional. Methods: There were 149 patients with CKD routinely submitted to HD that answered a questionnaire adapted (Medical Results Survey; SF-36) about the presence of symptoms during and after the HD sessions, main diseases concomitant, and the presence of factors that influence the quality of life. Results: According to the multivariate analysis, the presence of symptoms after the HD contributes to a decrease in the quality of life $(p=0.04)$. However, emotional well-being was positively associated with social activities $(p=0.01)$. The daily activities and the absence of concomitant diseases are associated with good health and, therefore, a better quality of life for patients with CKD $(p<0.05)$. Patients with chronic diseases such as hypertension and diabetes should be better observed, since such illnesses are always associated with renal dysfunction. Conclusion: The results of the present study demonstrate that the chronic renal patients should be inserted into social environments and should perform daily activities despite the limitations of the treatment since an active lifestyle contributes positively to their well-being and quality of life.
\end{abstract}

Keywords: Kidney Diseases. Renal Dialysis. Comorbidity.

\section{RESUMO}

Objetivo: O objetivo deste estudo foi avaliar os fatores físicos e sociais que influenciam a qualidade de vida de pacientes com doença renal crônica (DRC) em hemodiálise (HD). Modelo de estudo: Descritivo e transversal. Métodos: Foram incluídos 149 pacientes com DRC rotineiramente submetidos a HD que responderam ao questionário adaptado (Medical Results Survey; SF-36) sobre a presença de sintomas durante e após as sessões de HD, principais doenças

1. Universidade Federal do Piauí, Departamento de Biomedicina. Campus Ministro Reis Velloso. Parnaíba, PI, Brasil.

2. Universidade Federal do Triângulo Mineiro, Instituto de Ciências Biológicas e Naturais, Uberaba, Minas Gerais, Brasil.

3. Universidade Federal do Triângulo Mineiro, Departamento de Patologia. Uberaba, Minas Gerais, Brasil
CorRespondencia: Fernanda Machado Fonseca. Universidade Federal do Piauí, Departamento de Biomedicina, Campus Ministro Reis Velloso. São Sebastião Avenue, 2819, Reis Veloso, 64204-035 - Parnaiba, Piauí.

Recebido em 05/02/2018 Aprovado em 26/06/2018 
concomitantes e presença de fatores que influenciam a qualidade de vida. Resultados: De acordo com a análise multivariada, a presença de sintomas após a HD contribui para uma diminuição da qualidade de vida $(p=0,04)$. Entretanto, o bem-estar emocional foi positivamente relacionado com as atividades sociais $(p=0,01)$. As atividades diárias e a ausência de doenças concomitantes estão associadas com uma boa saúde e assim, a uma melhor qualidade de vida dos pacientes com DRC $(p<0,05)$. Pacientes com doenças crônicas como hipertensão e diabetes devem ser melhor acompanhados, uma vez que, estas doenças estão constantemente associadas a disfunção renal. Conclusão: Os resultados do presente estudo demonstram que os pacientes crônicos renais devem ser inseridos no ambiente social e devem realizar atividades cotidianas, apesar das limitações do tratamento, uma vez que um estilo de vida ativo contribui positivamente para a melhora da qualidade de vida.

Palavras-chave: Doença Renal. Diálise Renal. Comorbidade.

\section{INTRODUCTION}

Chronic kidney disease (CKD) is a pathology that represents a significant public health problem, whose prevalence has increased considerable worldwide ${ }^{1}$. Patients with renal disease progressing to the chronic stage have several clinical aftereffects, some of which are partially corrected by renal replacement therapy. Additionally, these patients present a higher mortality rate and a dropin quality of life due to several symptoms that influence performance in daily activities ${ }^{2}$.

The causes of CKD include diabetic nephropathy, present in both type 1 and type 2 diabetes, or may be related to non-diabetic causes such as vascular, glomerular, tubulointerstitial and cystic ${ }^{3}$. The groups at risk for the development of CKD are individuals older than 50 years, smokers, hypertensive, diabetic, obese, or who have a family history of renal failure ${ }^{4}$. Typically, the signs of the disease appear gradually and are nonspecific, such as fatigue, hypertension, nausea, shortness of breath, swelling in the limbs, decreased urine production and glomerular filtration rate, and albuminuria, which is used in the diagnosis 5 .

According to the Brazilian Chronic Dialysis Census, hypertension corresponds to $34 \%$ of the causes of CKD in Brazil, which makes it the main one among those related to the vascular situation and is also considered the leading cause of mortality in end-stage chronic renal patients in the United States ${ }^{6,7}$. Diabetes is presented in 30\% of the cases, and Chronic Glomerulonephritis in
$9 \%$. Polycystic kidneys account for only $4 \%$ of the causes of CKD, and $11 \%$ of cases of chronic renal failure have no definite cause ${ }^{6}$.

There are some alternative treatment methods for chronic kidney patients, with hemodialysis (HD) being the most used and adopted by approximately $90 \%$ of the population in the end stage of the disease ${ }^{2}$. Hemodialysis is a therapeutic modality that aims to remove catabolites from the organism through the extracorporeal circulation of blood in an equipment containing the dialysis solution. The blood leaves the body and runs through tubes to the dialyzer, where it is filtered before returning to the body of the patient. This therapeutic option demands a great disposition of the patients and their relatives since it is performed three times a week, with an average duration of 3 to 4 hours. It also accompanies several risks, such as cardiovascular complications, skeletal, endocrine, inflammatory, neoplasias and psychological ${ }^{8}$, to which the patients become more susceptible. Some side effects are common during the hemodialysis treatment such as dizziness, drowsiness, nausea, muscle cramps, headache and lack of appetite $^{9}$. In Brazil, it is estimated that 39,714 chronic renal patients started dialytic treatment in 2016, a higher number when compared to 2015 ( $n=$ $36,571)$. Diabetic nephropathy was present in approximately $41 \%(n=16,309)$ of the new cases of patients who started dialysis in the last year ${ }^{6}$.

The kidney transplant is another therapy option for chronic kidney patients and is associated with better improvement in the quality of life. 
However, there is limited availability of organs, and when available there are still several selection criteria that make transplantation a challenge among treatment options ${ }^{10}$. Between the years of 2011-2014, there were 32,499 patients in the transplant row in Brazil ${ }^{11}$ and in 2016, a total of 5,492 kidney transplants were performed in the country ${ }^{12}$.

In Brazil, the estimated number of patients undergoing renal replacement therapy due to hemodialysis in 2016 was more than 122,000. This value represents an average increase of $6,3 \%$ concerning the past five years, which shows the gradual growth of incidence of patients with this pathology. The hemodialysis remains the most preferred therapeutic option $(92.1 \%)^{6}$.

A study carried out in the city of São Paulo evaluated the quality of life of patients in HD and demonstrated that those with other types of disease concomitant to CKD such as Diabetes mellitus and with advanced disease presented low physical fitness. Socio-demographic factors such as age, sex, and occupation also contributed to the decrease in the quality of life of some patients. Additionally, many patients reported having a significant impact on their daily activities at the onset of the disease, however, during treatment they began to adapt to the new condition. Furthermore, it has been demonstrated that health professionals are concerned about dialysis patients, considering that the life of these patients is very restricted ${ }^{13}$.

Despite limited information about the quality of life of patients with CKD and their relation to the degree of disease, it appears to be more limited than in the general population, but there is an improvement when compared to patients receiving hemodialysis treatment ${ }^{14}$. Thus, the present study evaluated the quality of life of patients with CKD undergoing hemodialysis treatment in institutions of the state of Piauí for a better understanding of how this new condition interferes in the social and emotional life of these individuals.

\section{METHODS}

This descriptive and cross-sectional study was approved by the Research Ethics Committee of the Federal University of Piauí. It was developed in treatment institutions of chronic renal patients, after signing the Term of Consent, in which contained information about the ethical aspects of the research and the voluntary participation of the patients.

From December 2016 to July 2017, we selected chronic renal patients attending in two renal treatment clinics in different towns; one of them was located in Parnaíba and the other in Campo Maior, Piauí, Brazil. All patients were informed about the purpose of the research, and those who agreed to participate in the study signed the Informed Consent Term according to the resolution 196/96 dealing with research involving human beings, being guaranteed anonymity and withdrawal of participation at any time. Patients under the age of 18 years, those who for some reason did not complete the interview, or who did not agree to participate, and patients who for some reason did not sign the Free and Informed Consent Term, were excluded.

Data collection was performed using a questionnaire adapted from the Medical Outcome Survey - Short Form 36 (SF-36) ${ }^{15}$ about the quality of life of chronic kidney disease patients, which included demographic, socioeconomic, pathological aspects, clinical characterization of patients and main complications presented during the hemodialysis sessions.

The data were analyzed in SPSS (Statistical Package for Social Science) software version 23.0. For comparison purposes, the chi-square test was used with significance level $p<0.05$.

\section{RESULTS}

A total of 149 patients undergoing hemodialysis were included, of which $92(61.7 \%)$ patients came from the UNIRIM clinic in Parnaiba, Piauí, Brazil, and 57 (38.2\%) patients came from the Instituto do Rim (IRCM) in Campo Maior, Piauí, Brazil.

The age of the patients ranged from 18 to 87 years, with an average of 54.11 (SD \pm 15.38 years). Regarding gender, 78 (52.3\%) patients were men and $71(47.7 \%)$ patients were women. When we evaluated the level of education, 44 $(29.5 \%)$ and $19(12.8 \%)$ patients had incomplete and complete elementary school, respectively, and 
$42(28.2 \%)$ were illiterate. Also, $18(12.1 \%)$ and $14(9.4 \%)$ patients had complete and incomplete secondary school. Only 12 (8.1\%) had higher education.

The mean of time in years in which patients underwent hemodialysis treatment was 4.73 years (SD \pm four years), and 61 (40.9\%) patients reported being on therapy for a period of one to three years. Other results showed that 37 (24.8\%) patients were treated for at least four to six years, $26(17.4 \%)$ patients reported being treated for a period of seven to ten years, $13(8.7 \%)$ patients were on HD treatment for more than ten years, and $12(8.1 \%)$ patients started treatment less than one year ago. Furthermore, 131 (87.9\%) patients reported feeling some symptoms such as cramp, headache, shortness of breath, and others during the HD session, while 128 (85.9\%) patients described some symptoms after treatment $(p=0.00)$ (Table 1$)$. Of the 149 patients, $117(78.5 \%)$ have shown the presence of some sign before and after the HD sessions.

Patients with CKD were questioned about how they evaluated their health. In general, 108 $(72.4 \%)$ reported good health, of which 51 $(47.2 \%)$ were on HD treatment for 1 to 3 years, and $11(10.2 \%)$ patients were on treatment for more than ten years $(p=0.03)$. Thirty-nine $(95.1 \%)$ of the 41 patients who considered them- selves not to have good health also presented symptoms after HD sessions $(p=0.04)$. According to the emotional state, $14(73.7 \%)$ of the 19 patients who considered themselves to be sad reported not being able to perform daily activities such as housekeeping, cleaning and loading furniture $(p=0.01)$. Also, $11(57.9 \%)$ said they did not have social life $(p=0.01)$. An emotional improvement was detected after the onset of HD treatment in 101 (93.5\%) of the 108 patients who reported good health $(p=0.00)$.

Regarding the presence of other concomitant diseases along with CKD, 107 (71.8\%) of the 149 patients studied had a concomitant disease. Hypertension ( $\mathrm{n}=99 ; 66.4 \%$ ) was the most prevalent, followed by the presence of diabetes $(\mathrm{n}=32 ; 21.5 \%)$, among others $(\mathrm{p}<0.00)$ (Table 2 ). According to the multivariate analysis, the performance of daily activities, as well as the absence of another concomitant disease contributes to the patients' good health $(p<0.05)$ (Table 3$)$.

When we evaluated the lifestyle of the patients, $100(67.1 \%)$ of them reported following some diet or food restriction, ten $(6.7 \%)$ were smokers, and eight (5.4\%) patients reported consuming alcohol frequently. The service of the employees provided at the treatment clinics was satisfactory for $123(82.6 \%)$ patients, while 26 (17.4\%) patients showed dissatisfaction.

Table 1:

Symptoms presented by patients during or after hemodialysis (HD) sessions.

\begin{tabular}{lcccc}
\hline \multirow{2}{*}{ Symptoms } & \multicolumn{2}{c}{ During HD } & \multicolumn{2}{c}{ After HD } \\
\cline { 2 - 3 } \cline { 5 - 5 } Muscle cramps & $\mathrm{N}$ & $\%$ & $\mathrm{~N}$ & $\%$ \\
Headache & 73 & 49.0 & 54 & 36.2 \\
Itchy & 60 & 40.3 & 52 & 34.9 \\
Numbness & 47 & 31.5 & 44 & 29.5 \\
Shortness of breath & 38 & 25.5 & 47 & 31.5 \\
Nausea & 26 & 17.4 & 32 & 21.5 \\
Dizziness & 33 & 22.1 & 42 & 28.2 \\
Absence of symptoms & 34 & 22.8 & 51 & 34.2 \\
\hline
\end{tabular}

$\mathrm{p}<0.05$ 
Table 2:

Prevalence of concomitant diseases of chronic renal patients on hemodialysis treatment.

\begin{tabular}{|c|c|c|}
\hline \multirow[b]{2}{*}{ Concomitant disease ${ }^{1}$} & \multicolumn{2}{|c|}{ Patients } \\
\hline & $\mathrm{N}$ & $\%$ \\
\hline Hypertension* & 99 & 66.4 \\
\hline Diabetes* & 32 & 21.5 \\
\hline Heart diseases & 8 & 5.4 \\
\hline Gastritis & 7 & 4.7 \\
\hline Prostate Disease & 4 & 2.7 \\
\hline Stroke & 4 & 2.7 \\
\hline Spine problems & 3 & 2 \\
\hline Lupus & 3 & 2 \\
\hline Rheumatic diseases & 3 & 2 \\
\hline Anemia & 2 & 1.3 \\
\hline Thyroid disorders & 2 & 1.3 \\
\hline Hypercholesterolemia & 2 & 1.3 \\
\hline Asthma & 2 & 1.3 \\
\hline Osteoporosis & 2 & 1.3 \\
\hline Depression & 1 & 0.7 \\
\hline
\end{tabular}

${ }^{*} \mathrm{p}<0.05 .{ }^{1}$ Some patients had two or more concomitant diseases

\section{DISCUSSION AND CONCLUSION}

Chronic Kidney Failure is a growing public health problem, especially among the elderly and adults. This pathology leads the patient to a progressive decline in renal capacity, which can result in limitations in performing daily activities reflecting on their quality of life ${ }^{12}$. According to the Brazilian Nephrology Society Census ${ }^{6}, 57 \%$ of patients undergoing dialysis treatment are men, data similar to the present study where the prevalence of males was $52.3 \%$. The mean age of the patients was 54.11 years, which corroborates with data from the Brazilian Society of Nephrology, where the mean age of patients with CKF is 53.3 years ${ }^{6}$. Also in the study by Oller et al. (2012) the mean age of the chronic renal patients was 58.1 years.

The HD treatment contributes to a sedentary lifestyle and functional deficiency, since the daily life of the patient becomes monotonous and restricted, reflecting directly on the quality of life ${ }^{16}$. In our study, $95 \%$ of the patients who reported the presence of any symptom after the HD sessions considered themselves to be in poor health

Table 3:

Variables associated with the good health of chronic renal patients.

\begin{tabular}{|c|c|c|c|c|c|}
\hline \multirow[b]{3}{*}{ Variables } & \multirow[b]{3}{*}{$\mathrm{N}(\%)$} & \multicolumn{4}{|c|}{ Good health $(n=108)$} \\
\hline & & \multicolumn{2}{|c|}{ Univariate } & \multicolumn{2}{|c|}{ Multivariate } \\
\hline & & $\mathrm{P}$ & OR $(95 \% \mathrm{Cl})$ & $\mathrm{P}$ & OR $(95 \% \mathrm{Cl})$ \\
\hline Daily activities & & 0.00 & $3.66(1.70-7.86)$ & 0.00 & $3.17(1.41-7.09)$ \\
\hline Yes & $68(63.0)$ & & & & \\
\hline No & $40(37.0)$ & & & & \\
\hline Social activities & & 0.06 & $2.02(0.95-4.30)$ & & \\
\hline Yes & $80(74.1)$ & & & & \\
\hline No & $28(25.9)$ & & & & \\
\hline Good sleep & & 0.17 & $1.65(0.79-3.44)$ & & \\
\hline Yes & $71(65.7)$ & & & & \\
\hline No & $37(34.3)$ & & & & \\
\hline Other diseases & & 0.01 & $0.87(0.78-0.97)$ & 0.03 & $0.88(0.79-0.99)$ \\
\hline Yes & $18(16.7)$ & & & & \\
\hline No & $90(83.3)$ & & & & \\
\hline
\end{tabular}

Variables with $\mathrm{p}$ values $<0.25$ in the univariate analysis were included in the logistic regression model for multivariate analysis. Values of $p<0.05$ in the multivariate were considered significant. 
status. The most frequent of the symptoms (36.2\%) was the presence of muscle cramps that predominate in the lower limbs, followed by a headache $(34.9 \%)$, which may be associated with hypertension. Patients have also reported symptoms such as itching, dizziness and nausea, however, nausea has not yet been defined, but may be related to the rapid removal of urea from the blood ${ }^{17}$, which occurs in some HD sessions. Furthermore, the presence of chest pain in patients with CKD after HD was associated with reduced sleep quality. Studies have shown that the development of symptoms during and after the HD session influences the quality of life of chronic renal patients $18,19,20$.

When we evaluated the lifestyle, $6.1 \%$ of the chronic renal patients reported being smokers, and $5.4 \%$ are consumers of alcoholic beverages. This low prevalence of smoking may be associated with patient insecurity in revealing such information since the consumption of alcoholic beverages is inappropriate for chronic renal patients. It is well known that smoking increases the risk of CKD and the disease progression become more pronounced for individuals smoking 15 or more packs of cigarettes a year ${ }^{21,22}$.

The presence of concomitant diseases such as hypertension and diabetes may also be responsible for the renal failure. Concerning diabetes, mainly type II, it has contributed to the development of the chronic renal insufficiency ${ }^{23}$. Additionally, counseling to discontinue antihypertensive medication in the pre-dialytic period also helps to elevated blood pressure during the dialysis procedure ${ }^{24}$.

Some studies demonstrated that there was an improvement in patients' health over time, due to their adaptation to treatment ${ }^{25}$. This finding corroborates with our results, since $84.61 \%$ of the patients who had been treated for more than ten years reported excellent health, whereas, among the patients who underwent treatment less than one year, only $50 \%$ affirmed having good health. The quality of life of patients with CKD is related to family coexistence and social relationships, as many tend to isolate themselves socially, which affects their well-being.

Among the patients who reported not having good health in the present study, the major- ity usually do not have a social life. Studies have shown that social life can act as a protective action in stress situations, thus avoiding possible adverse effects in patients, improving the psychological state in depressive individuals and functioning as a stimulus for the patient to attend the sessions of hemodialysis ${ }^{26}$.

In the present study, 101 (67.7\%) patients reported feeling good or happy with HD. During the interviews, it was possible to notice that the patients who have been in treatment for a long time feel conformed, whereas those with less than one year presented a feeling of concern and not acceptance in becoming dependent of the relatives. Thus, over the years, the emotional aspect of many patients tends to improve. Besides, some studies consider that the hope of performing renal transplantation is essential, since it positively influences the psychological well-being of many patients ${ }^{26}$.

The multivariate analysis of our study demonstrated that factors such as the presence of daily activities and the absence of concomitant diseases are directly related to the quality of life of the chronic kidney patients evaluated. Studies have shown that patients with CKD and with low quality of life have little incentive for daily activities $^{14,16,25}$. Regarding comorbidities, studies report that hypertension and diabetes can affect other organs and consequently negatively influence the quality of life of the individuals. It is important to emphasize the need for adequate treatment of concomitant diseases to improve the quality of life of patients with $\mathrm{CKD}^{13,27}$.

The patients with CKD of the present study were satisfied with the health professionals and with the service of the clinics where the treatment is carried out. Doctors and nurses play an essential role in the procedure as they guide patients to make the right decisions to improve efficiency throughout the HD process, also warning about the possible consequences in cases of negligence ${ }^{24}$.

The CKD is a disease with increasing prevalence in our country, so it is essential to know and understand its consequences for the quality of life of the patients affected, as well as the effects caused by the substitutive treatment of hemodialysis. Simple measures that can improve the 
quality of life of patients with CKD should be stimulated, such as social activities and family interaction even with treatment limitations. In this sense, other studies are necessary to understand the best way to minimize the effects of physical and psychological symptoms, caused by both the disease and the treatment, seeking a better quality of life for the chronic renal patient.

\section{Conflicts of Interest:}

The authors declare no conflict of interest.

\section{REFERENCES}

1. González-Bedat MC, Rosa-Diez GJ, Fernández-Cean J M, Ordúñez P, Ferreiro A, Douthat W. National kidney dialysis and transplant registries in Latin America: how to implement and improve them. Rev Panam Salud Publica. 2015;38:254-60.

2. D’Onofrio G, Simeoni M, Rizza P, Caroleo M, Capria M, Mazzitello G, et al. Quality of life, clinical outcome, personality and coping in chronic hemodialysis patients. Ren Fail. 2017;39:45-53.

3. National Kidney Foundation. K/DOQI clinical practice guidelines for chronic kidney disease: evaluation, classification, and stratification. Am J Kidney Dis. 2002;39 (2 suppl 1):S1-266.

4. Kazancioðlu R. Risk factors for chronic kidney disease: an update. Kidney Int., Suppl. 2013;3:36871.

5. Stevens PE, Levin A, For the Kidney Disease: Improving Global Outcomes Chronic Kidney Disease Guideline Development Work Group Members. Evaluation and Management of Chronic Kidney Disease: Synopsis of the Kidney Disease: Improving Global Outcomes 2012 Clinical Practice Guideline. Ann Intern Med. 2013;158:825-30.

6. Sesso RC, Lopes AA, Thomé FS, Lugon JR, Martins CT. Brazilian Chronic Dialysis Census 2016. J Bras Nefrol. 2017;39:261-6.

7. Saran R, Li Y, Robinson B, Ayanian J, Balkrishman $R$, Bragg-Gresham J, et al. US Renal Data System 2014 annual data report: epidemiology of kidney disease in the United States. Am J Kidney Dis. 2015;66: S1-S305.

8. Obokata M, Negishi K, Sunaga H, Ishida H, Ito K, Ogawa $\mathrm{T}$, et al. Association Between Circulating Ketone Bodies and Worse Outcomes in Hemodialysis Patients. J Am Heart Assoc. 2017;6: pii: e006885.

9. Lopes AA, Elder SJ, Ginsberg N, Andreucci VE, Cruz JM, Fukuhara S, et al. Lack of appetite in haemodialysis patients -associations with patient characteristics, indicators of nutritional status and outcomes in the international DOPPS. Nephrol Dial Transplant. 2007; 22: 3538-46.

10. Burkart J. The Future of Peritoneal Dialysis in the United States: Optimizing Its Use. Clin J Am Soc Nephrol. 2009; Supp1: S135-31.
11. Pestana JOM, Galante NZ, Silva HTJ, Harada KM, Garcia VD, Abbud-Filho M, et al. Kidney transplantation in Brazil and its geographic disparity. J Bras Nefrol. 2011;33:472-84.

12. Brazilian Association of Organ Transplantation. Brazilian Transplantation Registry. Organ transplantation in Brazil (2009 - 2016). v. XXI (4), 2016. Available from:http://abto.org.br/abtov03_ingles/ Upload/file/BrazilianTransplantationRēgistry/ Ingles2016-lib.pdf

13. Cruz MC, Andrade C, Urrutia M, Draibe S, Martins LAN, Sesso RCC. Quality of life in patients with chronic kidney disease. Clinics. 2011;66:991-5.

14. Paraskevi T. Quality of Life in Patients Undergoing Hemodialysis or Peritoneal Dialysis Treatment. J Clin Med Res. 2011;3:132-8.

15. Laguardia J, Campos MR, Travassos C, Najar AL, et al. Brazilian normative data for the Short Form 36 questionnaire, version 2. Rev Bras Epidemiol. 2013; 16:889-97.

16. Oller GA, Ribeiro R de C, Travagim DS, Batista MA, Marques S, Kusumota L. Functional independence in patients with chronic kidney disease being treated with haemodialysis. Rev Latinoam Enferm. 2012; 20,1033-40.

17. Tuchman S, Khademian ZP, Mistry K. Dialysis disequilibrium syndrome occurring during continuous renal replacement therapy. Clin Kidney J. 2013;6: $526-9$.

18. Sakkas GK, Karatzaferi C. Hemodialysis fatigue: just "simple" fatigue or a syndrome on its own right? Front Physiol. 2012; 3:1-4.

19. Edalat-Nejad M, Jafarian N, Yousefichaijan P. Diabetic nephropathy: a strong predictor of sleep quality in hemodialysis patients. Saudi J Kidney Dis Transplant. 2014;25: 774-80

20. Firoz MN, Shafipour V, Jafari H, Hosseini SH, Charati JY. Sleep quality and depression and their association with other factors in hemodialysis patients. Glob J Health Sci.2016; 8:53485.

21. Yacoub R, Habib $H$, Lahdo A, Al Ali R, Varjabedian L, Atalla G, et al. Association between smoking and chronic kidney disease: a case control study. BMC Public Health. 2010. 10,731.

22. Elihimas Júnior UF, Elihimas HC, Lemos VM, Leão Mde A, Sá MP, França EE, et al. Smoking as risk factor for chronic kidney disease: systematic review. J Bras Nefrol. 2014;36: 519-28.

23. Ghaderian SB, Hayati F, Shayanpour S, Beladi Mousavi SS. Diabetes and end-stage renal disease; a review article on new concepts. J Renal Inj Prev. 2015; 4:28-33.

24. Stern A, Sachdeva S, Kapoor R, Singh J, Sachdeva $\mathrm{S}$. High Blood Pressure in Dialysis Patients: Cause, Pathophysiology, Influence on Morbidity, Mortality and Management. J Clin Diagn Res. 2014;8:ME01ME04.

25. Mariotti MC, Carvalho JGR. Improving quality of life in hemodialysis: Impact of an occupational therapy program. Scand J Occup Ther. 2011;18:172-9.

26. Davison SN, Jhangri GS. The relationship between spirituality, psychosocial adjustment to illness, and health-related quality of life in patients with advanced chronic kidney disease. J Pain Symptom Manage. 2013;45:170-8. 